\title{
ACUMULACIÓN DEL CAPITAL Y SUBJETIVIDAD \\ Reflexiones alrededor de la vida cotidiana y el bienestar subjetivo en México
}

\author{
Capital Accumulation and Subjectivity: Reflections around the Everyday Life \\ and the Subjective Well-Being in Mexico
}

Jesús Moya Vela, Ernesto Menchaca Arredondo

Universidad Autónoma de Zacatecas, México

\section{KEY WORDS}

Capital Accumulation

Preoccupation

Everyday Life

Subjectivity

Subjective Well-Being

\begin{abstract}
From Marxist humanism (not disregarding the criticism of political economy that Marx himself developed), we analyze the conditions generated by the dynamics of capital accumulation in everyday life and subjectivity. A theorization of subjectivity is presented first from historical materialism in relation to accumulation, for which the idea of preoccupation developed by Kosík (1965) is used; second, it is argued how it is that this concretion of multiple moments determines forms of everyday life that make meanings of the world and well-being develop as an expression of preoccupation, for which it will be necessary to expose a series of indicators that allow empirically supporting the assertions of this paper.
\end{abstract}

PALABRAS CLAVE

Acumulación del capital

Preocupación

Vida cotidiana

Subjetividad

Bienestar subjetivo

\section{RESUMEN}

Desde el humanismo marxista (sin prescindir de la crítica a la economía política que el mismo Marx desarrolló), se pretende analizar las condiciones generadas por las dinámicas de acumulación del capital en la vida cotidiana y la subjetividad. Se presenta primero una teorización de la subjetividad desde el materialismo histórico en relación a la acumulación, para lo cual se recurre a la idea de la preocupación desarrollada por Kosík (1965); segundo, se argumenta cómo es que esta concreción de múltiples momentos determina formas de vida cotidiana que hacen desarrollar significaciones del mundo y del bienestar como expresión de la preocupación, para lo cual será necesario exponer una serie de indicadores que permiten sustentar empíricamente las aseveraciones que se proponen.

Recibido: 23/03/2020

Aceptado: 01/12/2020

\section{GLOBAL KNOWLEDGE}




\section{Introducción}

$\mathrm{L}$ a obra de Marx contempla muchas problemáticas de las sociedades capitalistas. Su esfuerzo principal, por lo menos durante un periodo de diez años previos a la publicación de la primera edición de El Capital (Marx, 1999a), fue siempre realizar una crítica a la economía política que era predominante en su época. Lo anterior, después de largas jornadas de duro trabajo y de estudio, lo llevó a desarrollar lo que es, sin duda, la mejor explicación al capitalismo: sentó las bases conceptuales que son indispensables hoy para entender las relaciones sociales capitalistas en cualquier lugar del mundo.

Lo anterior no significa que en el Materialismo Histórico, y especialmente en El Capital, encontremos una ventana que se asome a todos los rincones (a lo público y a lo privado; a lo personal y lo colectivo; a las formas de vida y las instituciones; etcétera). Lo que se advierte es la potencialidad teórica del pensamiento marxiano para que, metodológicamente, desde la investigación, pueda desarrollarse praxis para el entendimiento de las sociedades capitalistas en su recorrido histórico, que como tal, es acción y es teoría, es práctica y subjetividad. La totalidad, y el método dialéctico y materialista histórico que el autor citado desarrolló, no pueden desentenderse de las múltiples determinaciones que le componen a aquélla (Eagleton, 2017); por lo tanto, es inevitable poner atención en las particularidades de cada sociedad, grupo, región o nación para poder construir su entendimiento concreto.

Lo anterior presupone, entonces, que no hay una sociedad capitalista, sino por el contrario, que hay un capitalismo, históricamente determinado y originado en occidente, que, al instaurarse en todo especio geográfico como le ha sido posible, muestra además, su enorme plasticidad para echar a andar las relaciones fundamentales de toda sociedad capitalista (Marx, 2015); estas son: propiedad privada y enajenación vía la explotación de unos hombres sobre otros para la valorización del capital (Marx, 1999a). La acumulación, entonces, aunque fundamental, encontrará caminos históricos muy particulares para regionalizarse.

El posicionamiento espistemológico y ontológico que presupone la totalidad, llevó a
Marx a reflexionar sobre las múltiples determinaciones de la sociedad que él explicó en su obra. La subjetividad fue siempre un problema presente; incluso en algunos escritos le puso mucha atención, al grado de ser el eje principal, como lo son: La ideología alemana, sus escritos de 1984 o las tesis sobre Feuerbach; y en otras con un enfoque de menor relevancia teórica, pero siempre presente, como lo es su obra más importante titulada El Capital; o escritos políticos como La cuestión judía y El 18 brumario de Luis Bonaparte (Eagleton, 2017; Marx y Engels, 2014; Tarcus; 2015; Marx, 1999a; Marx, 1980).

En este trabajo, por motivos de investigación y de exposición, se presentará como eje de análisis la subjetividad. Sin dejar de observar la totalidad desde las posibilidades teóricas explicativas que aquí se pretenden; es decir, con sus justificadas limitaciones, se argumenta que aquélla es un elemento de importancia y codeterminación en el proceso de concreción de las sociedades capitalistas; más que un factor resultante o un epifenómeno de la consustancial materialidad de lo real, la subjetividad es una determinación que da forma a las sociedades capitalistas, mientras que de manera dialéctica, esta es también una correspondencia emergente de la concreción del capitalismo como un todo.

La vida cotidiana y la preocupación, implican formas de existencia que devienen dentro de un amplio entramado de relaciones de producción (Kosík, 1965). El intercambio de mercancías, la división social del trabajo, las relaciones de propiedad y la acumulación son también formas de estar en el mundo, y es en estas formas de estar en el mundo, que las clases sociales producen un universo simbólico y por ello de significados que les permiten construir una acepción de bienestar.

El artículo se desarrolla de la siguiente manera: primero, haremos un breve análisis sobre la subjetividad desde su acepción materialista y marxista, esto, sin pretender ser exhaustivo en la literatura, por lo que el trabajo va directamente a la propuesta que comprende el análisis derivado de la investigación de aquella en relación con los procesos de acumulación capitalista; segundo, se hace un esfuerzo por teorizar cómo es que lo anterior concretiza formas de vida cotidiana haciendo que las 
sociedades formen expectativas y significaciones respecto al presente, el futuro, la felicidad, etcétera, es decir, sobre el bienestar. Para esto último, se exponen algunos indicadores sobre el bienestar subjetivo en México, lo que permitirá demostrar los argumentos, pero además hacer un ejercicio de exposición del problema de investigación en dicho país.

\section{Acumulación y vida cotidiana: la subjetividad como elemento de la preocupación}

Parece ser que América Latina ha tratado de superar viejos juicios y prejuicios del pensamiento marxista (Kohan, 2009). Aquí no se pretende mostrar que la discusión es propia y que ahora comienza. Pero ciertamente, en la historia del pensamiento crítico marxista, se han desarrollado distintas apropiaciones de la obra del autor que nos ocupa. El economicismo es sin duda una forma de defender el verdadero método y razón de ser de la teoría marxista; lo mismo es el marxismo soviético de manual que las organizaciones obreras, las campesinas, los partidos políticos, los movimientos sociales y sus liderazgos tanto reprodujeron; lo es también el pensamiento de Althusser que autores y autoras como Marta Harneker desarrollaron para explicar la sociedad capitalista como una estructura; y por mencionar sólo una escuela más, lo fue también el desarrollismo que aseguraba que era inevitable transitar por un camino evolutivo que llevaría a las fuerzas productivas a generar la revolución mundial para instaurar el comunismo.

Los problemas que enfrentan estos enfoques, es decir, estos marxismos, entendidos como apropiaciones disciplinares y prácticas del pensamiento de Marx, son muy diferentes entre sí. Respecto al economicismo, inicialmente, se reconoce su lealtad a la economía política, dando prioridad al estudio de la producción, la circulación, la distribución y el consumo como ejes vertebradores de las investigaciones emanadas de él. Esto implica que no hay, o no debe haber, más marxismo que el que hace teoría e investigación económica.

El marxismo de manual dejó en la región un aprendizaje vulgar de este paradigma (Veraza,
2018). Ciertamente, no se reprodujo nada más en la práctica política, ya que la academia también comunicaba y enseñaba este marxismo. La ideología se entendió como la subjetividad en sí, que está particionada y configurada según la clase social de la cual es expresión. Esta confusión de la verdadera postura de Marx y Engels (2014), no reconocía a este concepto como definidor de relaciones políticas de dominación propias de una clase que explota y se contrapone a la esperanza de procesos de lucha a través de la conciencia que las contradicciones de la historia pueden constituir en el capitalismo.

El estructuralismo marxista, como sostiene Kohan (2009), dejó fuera la dialéctica, o bien, la ignoró y simplificó al capitalismo al entenderlo como una estructura con elementos que solamente se suman para formar el todo (no hay una verdadera explicación de las sociedades capitalistas como totalidades concretas, como lo entiende Kosík y el mismo Marx). El enfoque de Althusser, en efecto, fue uno de los más ocupados en el problema de la subjetividad en el capitalismo (Althusser, 2018; Therborn, 1987). $\mathrm{Su}$ famosísimo ensayo sobre los aparatos ideológicos dio nacimiento a toda una escuela de estudiosos de la ideología. Desafortunadamente, su introducción del psicoanálisis al materialismo marxista y su encono contra la dialéctica, lo llevaron, no únicamente, a desarrollar una teoría elemental sobre el capitalismo (donde hay una estructura y una superestructura como producto epifenoménico de la primera), sino que, además, propicio que algunos de sus pupilos fueran llevados fuera del marxismo por todo esto.

Un ejemplo muy significativo es Laclau y su posmarxismo. Entre su aparato crítico incluye la perorata lacaniana para combatir la teoría de clases del materialismo histórico (Laclau, 2012a; Laclau, 2012b). Se dice que el marxismo es reduccionista y economicista, porque no permite explicar procesos como las identidades, que el concepto de clase social es inoperante teóricamente, o que la idea de una sociedad sin Estado debido a la desaparición de clases es una mera entelequia.

El término posmarxismo implicaría que se ha logrado la superación y soterramiento de su paradigma adversario; el problema, creemos, es que confundió determinaciones materiales con 
determinación económica, lo cual no es lo mismo, y, como es posible entender en Eagleton (2015), determinación no es sinónimo de economicismo; también asumimos que clase social no es sinónimo de uniformidad subjetiva y que el concepto no niega la diversidad cultural e identitaria, por lo anterior es que se debe dejar de pensar en que las respuestas a la explotación del hombre por el hombre sean sin prescindir del Estado (las experiencias autonómicas pueden ser muy esperanzadoras en un presente que requiere pensar en nuevas relaciones sociales más allá del capitalismo). El error, entonces, de esta postura, es que la crítica al marxismo parte de un Marx mal entendido.

Por otro lado, aquello que se sabe sobre los últimos esfuerzos de investigación de Marx, apuntan no solo a que superó su pensamiento eurocentrista. En su vida se acercó al estudio de la cultura y la organización política de los campesinos rusos y de los pueblos asiáticos (Shanin, 1990). Ello da muestra de la importancia que tenían para sus investigaciones asuntos que no son únicamente económicos.

América Latina ha desarrollado grandes esfuerzos por integrar explicaciones teóricas sobre el capitalismo en la región. La teoría de la dependencia o la teoría del subdesarrollo son grandes ejemplos. En la reinterpretación que ha hecho Víctor Figueroa del subdesarrollo, por ejemplo, hay un gran esfuerzo por llevar la explicación de las condiciones económicas del subdesarrollo hasta las áreas del Estado, la democracia y las luchas de clases (1986). Se dirá entonces, que no hay un desconocimiento de las determinaciones no económicas en las investigaciones que el pensamiento marxista latinoamericano ha producido.

Sin embargo, se debe señalar que es necesario $\mathrm{y}$ urgente retomar, y profundizar, en los problemas de la subjetividad en México y en América Latina en general, para entender cómo es que en un sistema que pareciera mostrar una de sus más grandes crisis, no solo entendida como "puramente" económica, sino como una crisis de la totalidad que se refleja en distintas determinaciones del capitalismo, se producen procesos de lucha que pudieran trascender o no hacia un verdadero anticapitalismo; o bien, para explicar cómo es que la sociedad expresa también distintas configuraciones de la preocupación que hacen que la enajenación se cristalice en formas de vida que retroalimentan y reproducen el sistema capitalista. Ambos polos expresan dominación: el primero es resultado de su negación y superación, el segundo es su concreción vía su reproducción.

Karel Kosík definió la preocupación como un estado práctico y subjetivo que define al agente social en estado de sujeción y como parte del entramado en el cual su vida está inmersa en las relaciones sociales capitalistas. Implica formas de simbolizarse la existencia y mecanismos de acción para desenvolverse en ella de manera cotidiana. La preocupación también es los deseos y expectativas que los colectivos, las familias, los trabajadores, los jóvenes, etcétera (como parte de una clase), expresan desde el entendimiento y la significación que tienen del mundo como resultado de las relaciones sociales capitalistas. Es necesario considerar que estas relaciones se reproducen constantemente, y que también para la reproducción de su propia vida, los agentes se ven históricamente necesitados de involucrarse en contextos y entornos que están conformados por una compleja red de relaciones, interacciones y procesos de comunicación e intersubjetivación en un modo de producción. Hay que agregar, que para Kosík, esta dinámica es un reflejo de los procesos de enajenación que son consustanciales al capitalismo (Kosík, 1965).

La preocupación no es sólo una percepción o una explicación general que toda persona tiene de su propia existencia. Es una complementariedad de aspectos y efectos prácticos de los cuáles se produce la subjetividad y que le es concomitante. Debe entenderse, entonces, como praxis. Es a partir de estas condiciones materiales que cristaliza en formas de vida cotidiana. Debe puntualizarse que esta determinación es inicialmente el origen emergente de la preocupación, es decir, que se origina en determinaciones materiales, pero esta también se vuelve determinación que hace que la reproducción de la vida social y del capitalismo tengan continuidad.

La acumulación del capital genera cierto tipo de relaciones, conflictivas y contradictorias, pero también propias de una sociedad capitalista determinada, que hacen que aquella encuentre 
obstáculos en su camino o que se realice adecuadamente. Es importante repetir que el origen de emergencia de la preocupación no implica una determinación unilateral de un factor sobre otro, o que la subjetividad es solo un epifenómeno de las condiciones materiales y/o un lineal resultado "superestructural" desde la "estructura"; es decir, que no hay una explicación reduccionista ni un determinismo economicista en la exposición del concepto hecha por Kosík (1965).

Como se mencionó ya, la preocupación implica que en el capitalismo las relaciones sociales se presentan con enajenación. Ésta acontece bajo ciertas condiciones históricas determinadas. Es un proceso dialéctico de la conciencia, pero, más que un proceso meramente espiritual o subjetivo, este acontece a través de las relaciones sociales que la producción y el intercambio promueven. Parece ser que no es únicamente un desdoblamiento de la subjetividad, entonces, sino que es concomitante a su materialización como objetivación en el proceso de producción.

La objetivación del trabajo conlleva toda la creatividad de quien lo ejerce. Es praxis, y por ello se acompaña de acción y de conciencia, o de práctica y subjetividad. El trabajo se desenvuelve históricamente determinado bajo configuraciones específicas de las relaciones hombre naturaleza que permiten que, socialmente, los seres humanos den continuidad a su vida (Marx, 1980). Esto ha sucedido en toda la historia de la humanidad. El trabajo siempre le ha acompañado, pero los conocimientos, la cultura y las formas de vida que esto implica, han llevado también al desarrollo de las fuerzas productivas, modificando el trabajo y por ello las relaciones sociales de producción que le presuponen (Marx y Engels, 2014). Si la interpretación y exposición que Gordon Childe hizo de las revoluciones de las civilizaciones en lugares como Egipto o Mesopotamia es correcta (Childe, 1997), se vuelve evidente que el desenvolvimiento de las fuerzas productivas son co-determinantes de aspectos relacionados al conocimiento técnico, científico, religioso y político.

El capitalismo implica, de igual forma, relaciones de producción históricamente determinadas. Así, se presupone que la acumulación es en forma de capital, y para que el dinero, el trabajo, la mercancía y los medios de producción sean capital, es necesario, precisamente, en sus ciclos, que la producción haga que estos elementos generen valorización (Marx, 1999b). El trabajo se presenta frente a un ordenamiento de propiedad privada, pero, además, esa propiedad privada es principalmente sobre todos los medios de producción, o por lo menos sobre los más importantes, haciendo que el trabajo se convierta en la única pertenencia del desposeído. La relación capitalista genera acumulación al desapropiar del producto de su trabajo al obrero, y quedándose, además, con el excedente que produce más allá de la reproducción de la fuerza de trabajo y las condiciones que permiten dicha reproducción (Marx, 1999a). El capitalista podrá acrecentar su capital con ese plusvalor si las condiciones lo permiten (acumulará) (Marx, 1999b), y en ese esfuerzo, en un proceso amplio de acumulación capitalista, las vidas de las clases implicadas se ven trastocadas en su cotidianidad. Hay que acercarse al capítulo XXIV, la llamada acumulación originaria, de El Capital Tomo I (Marx, 1999a), para observar cómo este periodo histórico de la historia del capitalismo afectó la vida de obreros, campesinos, artesanos, aprendices, oficiales, etcétera; con uso de violencia por parte de los capitalistas.

Todo el proceso capitalista, en la producción, en sus tiempos de rotación, en la circulación y el consumo, está coordinado para hacer que, cuando un trabajador objetive su conciencia (Ilienkov), sea enajenándole todas las condiciones creativas de valor más allá de sus propias necesidades diarias; es decir, más allá de lo que requiere cultural, social e históricamente para respirar, andar, ser padre, ser hijo, divertirse o educarse. Dicho de otra manera: para la reproducción de su fuerza de trabajo y de las condiciones subjetivas que permiten su existencia.

La enajenación, en el capitalismo, acontece en este entramado de relaciones, y es motivada por una clase, la que enajena con fines de ganancia, o dicho de manera más coloquial, para su enriquecimiento y para su ceba. Y la acumulación y la reproducción del capital en escala ampliada (Marx, 1999b), conllevan que la clase trabajadora, la desposeída, deba ajustar su ritmo de vida a las necesidades del capital y bajo las 
condiciones históricas que permiten al capitalismo dicha acumulación.

\section{Capitalismo y subjetividad}

Ya planteada la relación entre acumulación capitalista y subjetividad, mediada por el concepto "preocupación" propuesto por Karel Kosík, expondremos ahora, y en el siguiente apartado, cómo es que el bienestar subjetivo es expresión de todo ello. Debe entenderse, por ello, a la primera parte de este artículo, como una demarcación teórica que permite, ahora en esta segunda parte, abordar empíricamente el problema.

La subjetividad no es una separación inadecuada entre sujeto $\mathrm{y}$ objeto. Las construcciones de objetos humanos existen como expresiones de un sistema simbólico más general, que se conforma en cultura y estas realidades no pueden separarse de las personas, quienes las asumen y traducen en prácticas sociales. Por lo tanto, no todo está determinado y definido por la estructura. Así, vista la subjetividad como:

Una producción simbólico-emocional de las experiencias vividas que se configura en un sistema que, desde sus inicios, se desarrolla en una relación recursiva con la experiencia, no siendo nunca un epifenómeno de esa experiencia. La subjetividad es una cualidad constituyente de la cultura, el hombre y sus diversas prácticas, es precisamente la expresión de la experiencia vivida en sentidos diferentes para quienes la comparten, constituyendo esos sentidos la realidad de la experiencia vivida para el hombre. (González Rey, 2012, p. 13)

Al definirse, como producciones simbólicasemocionales sobre sus experiencias, además, como formas y prácticas que se desarrollan en un espacio de organización social, hace que lo subjetivo no se pueda reducir al espacio individual, los diferentes entramados sociales en los que se encuentra inmersa la constitución individual definen una unidad inseparable entre subjetividad social e individual. Así, la subjetividad social se configura como un acontecimiento representacional y emocional que integra los procesos que se desenvuelven a un nivel macro y micro social, generando reconstrucciones subjetivas sobre los aspectos cotidianos en todas las esferas de la vida.

Para entender los desafíos contemporáneos es necesario el discernimiento sobre las relaciones, interacciones y formas que asumen, por un lado, la vida y por otro la política. Este entrecruzamiento tiene sus efectos en el marco del nacimiento del capitalismo, del Estado moderno y de la construcción de una visión antropocéntrica del mundo, a lo que se ha dado en llamar el nacimiento de la biopolítica (Maldonado, 1999). De ahí que la perspectiva de análisis que se plantea busque entender el bienestar como forma de vida, como bíos con un contenido concreto, que ha sido conformado y normalizado. Lo dado en el sentido de Wittgenstein (1999).

Históricamente, todo modelo político organizacional requiere de cierta participación/inclusión, aunque sea simbólica, para generar condiciones de vitalidad del modelo y mantener su vigencia. Ahora bien, el sentido subjetivo de lo político no está en las intenciones declaradas o en los discursos, sino, como lo señala Fernando Rey (2012), en los efectos que las políticas generan. Si bien, uno de los pilares de la política es la legitimidad, las políticas no se legitiman solo por los criterios que avalan las decisiones implantadas, sino también por las producciones subjetivas que generan y las aspiraciones de desarrollo/futuro que despiertan en los sujetos.

Bajo estas premisas aspectos como la salud, el crecimiento demográfico, las migraciones, los matrimonios, divorcios, abortos, etc., pasan al ámbito de una política sobre la vida social y no como decisiones individuales. Una biopolítica, el despliegue o relación entre política y vida, como articulaciones permanentes de estrategias para su regulación y funcionamiento, constituyendo así diversos mecanismos o dispositivos para regular el cuerpo social. Estos dispositivos pueden ser un conjunto heterogéneo de mecanismos que componen desde discursos, narrativas, hasta instituciones. Un dispositivo red que da coherencia al entramado social. Este dispositivo es el que se analiza desde la perspectiva del bienestar subjetivo, permitiendo dibujar el sistema de mecanismos operantes que le dan sentido al poder constituido de la democracia. 
Así, en ciertos momentos cuando la población se cuestiona sobre su propia constitución sociopolítica, operan diversas alternativas, desde el conformismo, la sumisión hasta la novedad instituyente y la ruptura. El propio hecho de preguntarse sobre sí mismo, de realizar acciones de reflexión devienen en subjetividad con capacidad de acción deliberada o de ruptura como potencia; esta subjetividad es adjetivada como política. Esta conforma nuestra cultura, produce no solo símbolos y emociones sino actuaciones políticas, pero escapa a las ataduras de sus propios productores y su naturalización se rompe aún después de ser institucionalizada en formas políticas.

Por otro lado, el trabajo como subsunción de subjetividad, el que padecemos en la sociedad contemporánea, que día a día consume nuestras energías, se desarrolla bajo múltiples y diversos mecanismos de dominio en una lógica de acumulación dislocada. En una racionalidad del trabajo capitalista, que aprisiona, se arrancan nuestras fuerzas, trata de quitarnos todo, queriendo absorberlo todo, no solo nuestros cuerpos, sino también hacer uso de nuestros pensamientos; la preocupación, entonces, es también reflejo de la dominación. Sin embargo, a pesar de las sofisticadas formas de sujeción del capitalismo para obtener la potencia de las personas, y someterlas a la intensidad del trabajo capitalista, brota por todas partes la naturaleza del trabajo como creación creativa, común y liberadora.

Una perspectiva sobre el trabajo puede verlo como fuente destructiva de esta sociedad y/o como una propuesta de afirmación de otra. Si se reconoce que el trabajo está presente en todas las mercancías y es la sustancia común de todas las actividades productivas. Sin embargo, para Marx (1999a) a la hora de expresar la proporción del tiempo necesario para la producción de una determinada mercancía, tratando de encontrar las leyes del valor, deja plasmado el modo de efectuar las elecciones sociales, el orden subyacente bajo las emergencias culturales existentes.

Esta interpretación coloca al sujeto colectivo por encima de la individualidad, sin dejar de reconocer al individuo, le reconoce inspeccionando el bien común como tarea propia de los sujetos. Esto, en principio, rompe con la visión atomizada sobre el bienestar y reconstruye el papel del trabajo como obra colectiva de recreación humana. Además, se le confiere una tarea personal a la búsqueda de la felicidad del otro y de su propio bienestar. Ciertamente, el capital no permite la generalización de este tipo de comportamientos, pero existe, como en toda época, a pesar de los múltiples escollos. Se trata de una conquista del hombre consigo mismo, en el cual el capital busca ocultar esa naturaleza humana, donde regularmente se ponen en evidencia las manifestaciones de su encierro y que podría buscar romper la ceguera provocada por la intensificación y mistificación del individualismo egoísta.

En primer término, las clases sociales se han transformado. Antes delineadas dentro de las sociedades industriales, definidas bajo grandes grupos o estamentos en función de la clara presencia laboral, se podían distinguir el tipo de trabajo o las condiciones sociales y económicas que generaba, su forma de vida estandarizada, normada a esa construcción con un imaginario que se ofertaba. Ahora, las formas de explicar la familia, el trabajo, educación, servicios, Estado, gobierno, seguridad social $\mathrm{y}$, sobre todo, la idea-imagen de futuro se sostienen bajo nuevas configuraciones de las clases sociales y ante una nueva división social del trabajo más allá de la industria.

Lo que se destruye frente a nuestros ojos es el viejo Estado, construido bajo los procesos de producción ligados al trabajo anteriormente articulado a una dinámica industrial con una estructura de disciplina de la sociedad como administrador de la razón: la acumulación se torna muy distinta a como lo fue en los años maravillosos del capitalismo (periodo de posguerras).

El neoliberalismo, al transformar las formas de dominación y trabajo, pulveriza la antigua edificación. Se trata, como lo describe Giuseppe Cocco (citado en Negri et al, 2008, p. 44) de: "innovar la tecnología del mando para organizar la producción que ya está directamente dentro del tejido de las redes sociales [...] es la tentativa de subsumir la vida a los circuitos de la dinámica de la reproducción dentro del proceso de acumulación". Una dinámica que reconfigura las formas de inclusión y exclusión social.

Pero este neoliberalismo también se agota, aunque su dinámica aún predomina. Esto ha 
traído como consecuencia dos principales dinámicas de fragmentación, una para reorganizar el control social con el objetivo de integrar la vida como un todo dentro de la dinámica de acumulación $\mathrm{y}$, otra, la fragmentación como singularidad (Baudrillar, 2003).

$\mathrm{Al}$ fragmentarse en principio la actividad laboral en la producción de la riqueza y diluirse en la pluralidad de las actividades sociales, junto con ella, se modifica el patrón de productividad antes asido a la disciplina o la destreza, ahora incorporado masivamente el conocimiento como forma de producción de valor.

Asistimos también al cambio del carácter del consumo de la fuerza de trabajo como lo muestra Negri (2008) al pasar de lo material-físico a lo cognitivo, siendo este uno de los ejes actuales del desarrollo capitalista. Es decir, la subsunción de subjetividad, principalmente, a través del conocimiento y emociones humanas. El capitalismo se desarrolla mediante una apropiación creciente de esta capacidad cognitiva, no de forma individual sino colectiva o común, general (como diría Marx). Esta apropiación no nos hace iguales para el capital, pero sí nos proletariza a todos, porque ahora, como lo señala Negri, ya no hay obreros-técnicos en el sentido clásico de su identificación, sino, que todos somos obreros inter-conectados bajo este sentido.

Esta transformación del trabajo es lo que fragmenta todo. Las relaciones sociales antes tan sólidas se disuelven, las creencias se dispersan, las emociones se multiplican, la governance pierde su razón. Esta fragmentación ha traído nuevas formas de inclusión/exclusión con la movilización del trabajo el cual anteriormente implicaba integración. El trabajo iba junto a integración social y construcción de ciudadanía; con accesos a ciertos derechos políticos. Ahora se transforma, como bien lo muestra Giuseppe Cocco, citado en Negri (2008), para desaparecer esa dinámica como fenómeno inverso. Los excluidos, los proletarios, son movilizados productivamente sin integración social. Esto significa, tendencialmente, presenciar un proceso donde los excluidos y, en este sentido la mayoría de la población, está siendo trasladada a la producción, pero sin dinámicas de subordinación asalariadas, sin integración social ni política. Los datos de la Organización Internacional del Trabajo revelan un alejamiento con respecto al modelo estándar de empleo, en cuyo marco los trabajadores percibían un sueldo o un salario en una relación de empleo dependiente con respecto a sus empleadores, tienen un trabajo estable y trabajan a tiempo completo. El modelo es cada vez menos predominante: menos del 45 por ciento de los trabajadores asalariados tienen un empleo bajo este modelo y la tendencia va a la baja. Es decir, en todo el mundo 6 de cada 10 trabajadores asalariados están ocupados en formas de empleo a tiempo parcial o temporal (ILO, 2015). Ahora bien, si el trabajo es productivo sin ser subordinado en el sentido clásico visto como empleo formal se generan las condiciones, concordando con el anterior autor, para convertirse en una actividad completamente "libre", que, a su vez junta, mezcla; entonces, también se hibrida liberación y emancipación.

Además, si el capital es una relación, entonces no es, a su vez, la única alternativa. Producir vida no sólo es hacer hijos, decía Judith Revel (2008); es una forma, pero hay otras como: "el hacer comunidad, luchar juntos, inventar formas de solidaridad y modificar la relación con el otro; todo eso es producir vida, todo eso es la ontología" (Revel, 2008, p. 120). Esta producción, en los hechos, es una forma de resistencia al capital que producirá nuevas formas de vida; la autora la denomina como una "ontología de la multitud".

Esta producción de formas de vida está anclada en última instancia al trabajo vivo, como lo señala Luis Tapia (2008), ya que los sujetos, bajo diferentes formas de relación social despliegan su conocimiento para producir la materialidad a través de la cual interactuamos. Recordemos que el principal motor de las fuerzas productivas es la forma de la relación social más que el capital constante, como puede ser la tecnología. Estas formas de productividad también despliegan capacidades de organización y resistencias, como lo señala el autor, formas de multitud o fusión de masa.

En este sentido el trabajo vivo se auto-valora, en términos de su experiencia colectiva, y eso por sí mismo genera nuevas formas de acción colectiva. Es esta autovaloración colectiva es la que ha puesto en crisis al Estado, porque la 
dominación política neoliberal pasa por la desvaloración de lo individual y colectivo para lograr el efecto de hiperindividualización y fragmentación, y con ello mantener la atomización y desorganización política, por lo tanto, como lo apunta Tapia (2008), la autovaloración es un elemento clave de la constitución de sujetos políticos. Es a través de este proceso de despojo de autovaloración que el capitalismo subordina para impedir la organización social y la apropiación política de los actos de los propios sujetos.

Esta descripción de la transformación actual del mundo, el cual se transforma en todos lados, en una interminable andanada de irrupciones. Vemos que el trabajo es el principal motor de esas rupturas de lazos sociales y productivos.

El hecho de que estemos más conscientes de la planetarización porque compartamos un mundo, no parece, por sí solo, mostrar una salida rápida para entender la pluralidad, mucho menos, encontrar un solo modelo para el hombre o lo que signifique una buena vida o una forma de vida modelo a imitar. De tal modo que el concepto de sociedad o pueblo, que antes designaban una determinada realidad social desde la sociología o la economía política, vistos como una totalidad imaginada o postulada, han sido derribados y perdieron sus límites diluyéndose. En la época actual de constante fluidez de las formas sociales, bajo una lógica de un mundo agotado como proyecto, la única salida posible es el acuerdo común sin destruir o asimilar las identidades en la diversidad. Por eso el gran desafío se enmarca dentro de un replanteamiento ético.

Además, podemos observar como la política vuelta acción institucionalizada, como ejercicio de la democracia liberal, se convirtió en un adiestramiento sobre su evaluación en términos de resultados. Esto ha permitido que las acciones gubernamentales se centren en la valoración final que hacen los electores en tiempos de elecciones y ejercicios de valoración ciudadana. Para ello, se hace uso de las acciones mediáticas y culturales, ejerciendo una predominancia sobre los medios de comunicación, lo que vuelve una práctica cotidiana el ejercicio de las apariencias para constituirse en una comunidad política imaginada y se colapsan las formas tradicionales de hacer política. Esto ha sido posible por la transgresión cotidiana de nuestro raciocinio a través de la fractalización de nuestras vidas y la subsunción de subjetividad, generando representaciones sociales inexistentes en la vida real. Existen más elementos que pueden integrarse, pero hasta aquí se puede cerrar está argumentación.

\section{Bienestar subjetivo en México}

Ahora señalamos cómo todos estos elementos macro propios del capitalismo, en relación a la subjetividad y la vida cotidiana, se ven reflejados en el bienestar subjetivo en México. Diversos especialistas coinciden en otorgar al bienestar subjetivo dos dimensiones: la cognitiva y emocional, que parecen complementar la percepción de juicios a largo y corto plazo, simultáneamente.

El bienestar psicológico se concibe como: "el esfuerzo por la perfección que representa la realización del propio potencial" (Lent, 2004, citado en, Omar et al., 2009, p. 71). En esta perspectiva sobresale la teoría de Ryff y Singer (1998), quienes sostienen seis dimensiones independientes de los valores culturales en la valoración de la forma como se ha vivido: autonomía, crecimiento personal, auto aceptación, propósitos en la vida, dominio del ambiente y relaciones positivas con los demás (Ryff, 1995). Como es observable, es en la preocupación, un estado existencial ante las relaciones sociales de producción propias de los procesos de acumulación capitalista (Kosík, 1965), que se recrea y expresa este bienestar subjetivo.

Los principales hallazgos sobre las concepciones del bienestar subjetivo permiten decir que es necesario considerar aspectos individuales y a la vez contextuales de una determinada sociedad, no ignorar lo que las personas desean y sienten, pero tampoco olvidar la conformación social que el sistema social impregna. Actualmente el marco de estudio del bienestar está tomando nuevas rutas y entramados, como bien lo describe Veenhoven (Octubre 22-24, 2006), situado en la discusión teórica sobre tres principales elementos: 1) como una evaluación anterior de lo que somos, 2) una constante comparación dentro de un estándar de nuestra vida y 3) como una 
experiencia afectiva. Estos aspectos son el resultado de un "balance general" o nivel de satisfacción que hacen las personas de sus oportunidades vitales: recursos sociales, recursos personales y aptitudes individuales. Dentro del curso de los acontecimientos a los que se enfrenta: privación-opulencia, ataqueprotección, soledad-compañía, etc., y aspectos relacionados a su experiencia.

Para este análisis, se recurrió a teorías de sistemas de segundo orden empleadas por Leydesdorff (2003), a través de su propuesta teórico-metodológica que permite la realización de mapas/red a partir de la exploración de factores cognitivos, comunicativos o conceptuales, entendidos como sistema de sentido en una ampliación de la teoría matemática. Ello permitió conocer la morfología de la red para observar la jerarquización conceptual del trabajo previo realizado a través de análisis factorial, derivado al análisis de redes sociales (ARS).

Los resultados del análisis factorial muestran que para una medición adecuada del bienestar es necesario tomar en cuenta los factores objetivos $\mathrm{y}$ subjetivos que den cuenta del progreso y desarrollo de una sociedad, en especial si estos permiten el sostenimiento de una democracia. Se trabajó con la Encuesta Mundial de Valores del 2012, datos México.

Interesa mostrar los componentes principales para ir exponiendo cómo se imbrican cada una de las variables complejas, y para identificar al final sus principales dimensiones. Los aspectos más relevantes son la satisfacción con la vida; la integran aspectos como la vida afectiva, la apariencia de las personas y su vida social y familiar, como un conjunto de aspectos subjetivos; pero también, la salud, el vecindario, su situación económica y su vivienda. Además, se incluyen la felicidad, la satisfacción con la educación que reciben, y aspectos ligados a las expectativas de logros personales en el futuro, a la seguridad personal, satisfacción con su trabajo y a una valoración global sobre su país.

El componente denominado Uso frecuente de computadora e internet y nivel de instrucción, integrado por el contacto por correo electrónico, el registro en redes sociales y el uso frecuente de computadora personal y su relación con el nivel de instrucción es negativa. Esto significa que este nivel no condiciona el uso de las redes sociales. Los resultados apoyan las consideraciones sobre las explicaciones diferenciadas entre felicidad y satisfacción con la vida, concepciones ligadas pero diferenciadas por la valoración en el tiempo que hacen las personas.

Hay aspectos integrados al componente sobre la reflexión interpersonal y aspectos lúdicos como ver un documental sobre historia, ciencia, o escuchar un programa de debate sobre la realidad del país. Aquí se aprecia un aspecto ligado a la actitud ecologista y protección de mascotas, incluyendo la voluntad de no tirar o quemar basura en la vía pública; de no usar, en lo posible, bolsas de plástico, de separar la basura inorgánica de la orgánica, y de hacer algo para evitar el abuso, sufrimiento y/o crueldad hacia los animales. La tendencia del desarrollo de una sociedad estaría ligada a servicios públicos que asuman compromisos con la protección de la naturaleza y con la posibilidad de las personas de tener momentos de reflexión sobre cosas importantes.

El anterior componente mantiene correlaciones con aspectos afines con la capacidad de las personas para obtener servicios públicos y acceso a servicios como la educación. Aspectos vitales para una cualificación alta del desarrollo social; no sólo se trata de la capacidad del régimen para ofertarlos sino de la capacidad de la población para acceder a ellos y, sobre todo, a la cohesión social existente en una sociedad para cubrirlos.

Un componente importante del nivel de desarrollo sigue siendo el nivel de discriminación y maltrato de las personas por su clase social, su edad, el color de su piel y otros aspectos físicos; o por su género. Incluyendo la capacidad de brindar a otras personas atención o cuidados personales, afecto y apoyo económico. Además, los indicadores sobre pertenencia a organizaciones civiles o no gubernamentales, de exalumnos y de superación personal o autoayuda, permiten una mayor cohesión social. Sin embargo, la variable de estrato social y la de ubicación geográfica son importantes a la hora de las evaluaciones sobre el bienestar.

Un aspecto a resaltar es la capacidad de las personas para apoyar económicamente a 
familiares y conocidos; esto genera mayor autoestima y libertad para tomar decisiones; además, haber experimentado felicidad en la niñez y en la adolescencia mantiene cierta estabilidad con relación al momento actual y a las expectativas de logros personales en el futuro. Los siguientes componentes están ligados a la pertenencia a una organización deportiva, a la disponibilidad de tiempo libre, a los logros y reconocimientos que han tenido las personas por su esfuerzo, y a la posibilidad de tomar decisiones importantes con libertad.

La discapacidad se relaciona principalmente con el uso permanente de muletas, silla de ruedas, andadera, bastón, o una prótesis en piernas o brazos, lo que sugiere que este componente está ligado a la vejez y a los accidentes. El número de personas de la familia con las que puede contar una persona en caso de presentarse una urgencia, constituye un aspecto importante del componente de apoyo social. Lo que las personas imaginan sobre la situación del país en los próximos 10 años esta correlacionado con la situación personal en términos de bienestar económico.

Figura 1. Network Visualization (mapping only) Kamada Kawai, Valores culturales de los mexicanos.

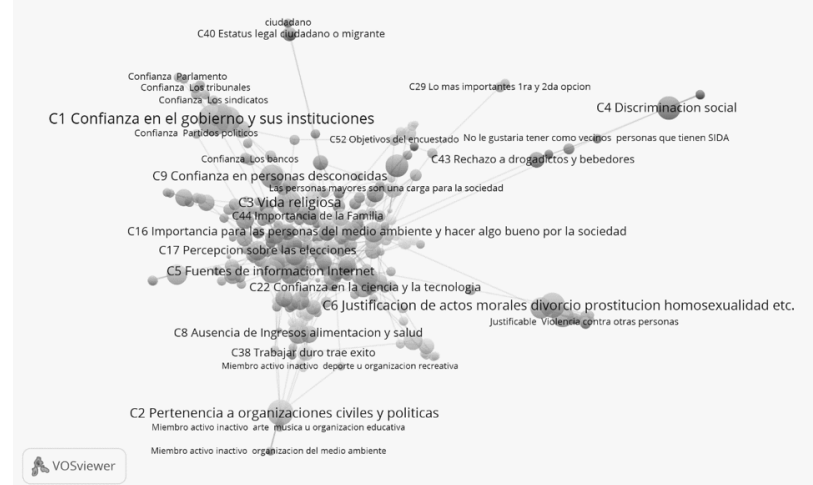

Fuente: Diseño propio con Ucinet6, Pajek 4 y VOSviewer en base a Encuesta Mundial de Valores (World Values Survey), 2012, datos México.

Un aspecto importante es la pertenencia a una religión, el cual tiene que ver con la promoción activa de una fe o de valores religiosos; donativos a organizaciones culturales o de ayuda a personas, especialmente si los donativos se hacen a instituciones que promueven la conservación de la cultura, de la naturaleza o de espacios urbanos. El componente de fuerza y confianza en sí mismo está principalmente definido por el grado de independencia y por la fuerza para enfrentar las adversidades de la vida; también interviene que le vaya bien personalmente y el modo como influye la situación que guarda el país en su propio bienestar.

Los componentes relacionados con aspectos negativos padecidos por los mexicanos son los niveles de alcoholismo o drogadicción, tener un familiar con alguna consecuencia producto de un accidente, recibir amenazas o agresiones físicas por parte de algún conocido, tener un padecimiento grave o mental, y sufrir amenazas de personas desconocidas. Algunos aspectos que son importantes por sí mismos son la frecuencia de las reuniones con amigos, el padecimiento grave de un hermano, su pareja o alguno de sus padres. Y dos aspectos relacionados con el maltrato por preferencias políticas y sexuales. Todo ello puede visualizarse en la red presentada en la imagen 1.

\section{Conclusiones}

Las formas de vida se adscriben a diferentes procesos. De los más determinantes, son las relaciones de producción a las cuales se está subsumido en sentido amplio. La actividad laboral, entonces, no se limita únicamente a la fábrica o la oficina, sino que, además, tiene sus efectos en los ritmos de vida y su cotidianidad. La preocupación es precisamente la forma en cómo los agentes sociales, desde sus acciones en un entramado de relaciones sociales de carácter capitalista, generan y les son generados procesos de subjetividad que les permiten ubicarse en el mundo social del cual son parte. Asumimos que los procesos de acumulación capitalista determinan en gran medida la diversidad de formas de vida que se encuentran en el interior de este modo de producción, tan caracterizado por la desigualdad y la explotación que se le derivan.

Esto se traslapa al bienestar subjetivo de la población, donde sus factores principales muestran cómo es que todos estos aspectos materiales de una sociedad capitalista determinada, como lo es la mexicana, complementan y son co-determinaciones de las relaciones sociales de producción; producción no sólo en términos de mercancías y/o valores de 
cambio, sino también como productoras de subjetividades, de enajenación y de identidades.

En México, las formas que actualmente asume la población están trascendiendo las ideas tradicionales que se tenían del bienestar y de las necesidades sociales, el sentido que asumen muestra una transformación profunda de las valoraciones que las personas hacen de la vida y de las instituciones, enmarcadas en las rupturas que acontecen por el proceso de modernización compulsiva en el que se vive y las nuevas bases sociales de una nueva sociedad que emerge, para lo cual es necesario considerar nuevas categorías para la descripción del desarrollo de las sociedades que consideren estás valoraciones de la población.

El capitalismo ha generado una racionalidad centrada en las mercancías, pero también una subjetividad centrada en la necesidad de un entramado burocrático organizacional, es decir una percepción de necesidad democrática liberal que produce valores y subjetividades para mantenerse estable, y aquí la co-determinación que tanto define a la preocupación.

Los niveles altos de satisfacción de los mexicanos, a pesar de sus relativas condiciones negativas en aspectos de su democracia, se pueden explicar no por el orgullo a sus instituciones, sino por el sometimiento histórico en el cual han estado y por su auto justificación al compararse con otras poblaciones de menor desarrollo, es decir, por sentir satisfacción con las apariencias.
Sin duda, la religiosidad es un elemento permanente y homogeneizador de la sociedad mexicana. Permea no solo la vida privada de las personas, sino el conjunto del funcionamiento social, principalmente en las relaciones laborales y políticas. No se sabe si exista o no una racionalidad decreciente. Las personas mientras más se alejan de sus cuestiones cercanas, en términos de democracia parecen tener una conducta irracional. Bajo esta óptica sobre el bienestar subjetivo lo que está más cerca de cuestiones personales y experiencias cotidianas influirá más sobre su bienestar y la aceptación del régimen político. Sin embargo, los niveles de satisfacción de la democracia tienen que ver con una distribución más justa de la riqueza y que se gobierne para bien de todo el pueblo. Bajo estas premisas, la generación de bienestar subjetivo es un elemento clave en la sostenibilidad de los regímenes que presupongan ser verdaderamente democráticos.

La concordancia en el bienestar subjetivo entre sectores sociales indica que estamos sometidos a los mismos mecanismos sociales, porque se pueden concebir de la misma manera las cosas, con el mismo aparato conceptual, sentir los mismos tipos de presiones sociales y tener los mismos valores. Es decir, compartir formas de vida, es pensar bajo los mismos principios, pero presupone el hecho de que se hable un mismo lenguaje, y hablarlo es también estar sometido a la misma clase de presión de los mecanismos sociales. 


\section{Referencias}

Althusser, L. (2018). Ideología y aparatos ideológicos de Estado. Práctica teórica y lucha ideológica. México: Tomo.

Argyle, M., y Martín, M. (1991). The psychological causes of happiness. En F. Strack, M, Argyle y N. Schwarz (eds.), Subjective well-being an interdisciplinary perspective. Great Britain: Pergamon Press.

Baudrillard, J. (2003). La violencia del mundo. Buenos Aires: Libros del Zorzal.

Childe, G. (1997). Los orígenes de la civilización. México: FCE.

Eagleton, T. (2015). Por qué Marx tenía razón. Barcelona: Ediciones Península.

- (2017). Materialismo. Barcelona: Península.

Figueroa, V. (1986). Reinterpretando el subdesarrollo. Trabajo general, clase y fuerza productiva en América Latina. México: Siglo XXI.

González Rey, F. (2012). La subjetividad y su significación para el estudio de los procesos políticos: sujeto, sociedad y política. En C. P. Echandía, Á. D. Gómez y Pablo Vommaro (eds.), Subjetividades políticas: desafíos y debates latinoamericanos. Colombia: Universidad Distrital Francisco José de Caldas/ Instituto para la Investigación Educativa y el Desarrollo Pedagógico - IDEP Consejo Latinoamericano de Ciencias Sociales - CLACSO.

ILO. (2015). World Employment and Social Outlook: Trends 2015, Switzerland, International Labour Organization (ILO).

Kohan, N. (2009). Nuestro Marx. Argentina, recuperado de https://www.nodo50.org/cubasigloXXI/taller/kohan_120110.pdf

Kosík, K. (1965). Dialéctica de lo concreto. México: Grijalbo.

Laclau, E. (2012a). La razón populista. México: FCE.

- (2012b). Debates y combates. Por un horizonte de la política. México: FCE.

Leydesdorff, L. (2003). A sociological theory of communication: The Self-organization of the knowledgebased Society. USA: Universal Publishers.

Maldonado, C. E. (1999). Esbozo de una filosofía de la lógica de la complejidad. En C. E. E. Maldonado (Ed.), Visiones sobre la complejidad, Vol. 1. Santafé de Bogota: Ediciones El bosque.

Marx, C. (1999a). El capital. Crítica de la economía política. Tomo I. México: FCE.

- (1999b). El capital. Crítica de la economía política. Tomo II. México: FCE.

- (1980). Manuscritos: economía y filosofía. Madrid: Alianza.

- (2015). Crítica al programa de Gotha. En H. Tarcus (comp.), Antología Karl Marx. Argentina: Siglo XXI.

Marx, K. y Engels, F. (2014). La ideología alemana. Crítica de la novísima filosofía alemana en las personas de sus representantes Feuerbach, B. Bauer y Stirner, y el socialismo alemán en sus diferentes profetas. Madrid: Ediciones Akal.

Negri, A. \& Hardt, M. (1994), El trabajo de Dionisos. Madrid: Akal Ediciones.

Negri, A.; Hardt, M.; Cocco, G.; Revel, J.; García Linera, A. \& Tapia, L. (2008). Imperio, multitud y sociedad abigarrada. Bolivia: Muela del diablo Editores/Comuna/CLACSO/Vicepresidencia de la República. Presidencia del H. Congreso Nacional.

Omar, A.; Paris, L.; de Souza Aguiar, M.; da Silva Almeida, S. H. \& Peña del Pino, R. (2009). Validación del inventario de bienestar subjetivo con muestras de jóvenes y adolescentes argentinos, brasileros $y$ mexicanos.

Revel, J. (2008). Biopoder y devenir mujer de la política. En T. Negri, M. Hardt, G. Cocco, J. Revel, A. García Linera y L. Tapia, Imperio, multitud y sociedad abigarrada. Bolivia: CLACSO.

Ryff, C. D. (1995). Psychological Well-Being in Adult Life. Current Directions in Psychological Science (Wiley-Blackwell), 4(4), E.U., Association for Psychological Science.

Ryff, C. D. \& Singer, B. (1998). Human Health: New Directions for the Next Millennium. Psychological Inquiry, 9(1), E.U., Routledge.

Shanin, T. (1990). El Marx tardío y la vía rusa. Marx y la periferia del capitalismo. Madrid: Editorial Revolución. 
Tapia, L. (2008). El proceso boliviano. La Paz, 9 de agosto de 2007. Auditorio del Banco Central de Bolivia. En T. Negri, M. Hardt, G. Cocco, J. Revel, A. García Linera y L. Tapia, Imperio, multitud y sociedad abigarrada. Bolivia:CLACSO.

Tarcus, H. (2015). Introducción. Leer a Marx en el siglo XXI. En H. Tarcus (comp.), Antología Karl Marx. Argentina: Siglo XXI.

Therborn, G. (1987). La ideología del poder y el poder de la ideología. España: Siglo XXI.

Veenhoven, R. (Octubre 22-24, 2006). How do we Assess How Happy we are? Tenets, implications and tenability of three theories, conferencia presentada en The New Directions in the Study of Happiness: United States and International Perspectives, University of Notre Dame, USA.

Veraza, J. (2018). Marx y la psicología social del sentido común. (Contribución a una teoría marxista del sentido común). México: Itaca.

Wittgenstein, L. (1999). Investigaciones filosóficas. España: Altaya. 